\title{
Prevalence of snoring and sleep breathing-related disorders in Chinese, Malay and Indian adults in Singapore
}

\author{
T.P. Ng*, A. Seow*, W.C. Tan**
}

Prevalence of snoring and sleep breathing-related disorders in Chinese, Malay and Indian adults in Singapore. T.P. Ng, A. Seow, W.C. Tan. (OERS Journals Ltd 1998.

ABSTRACT: This study investigated the prevalence of snoring and symptoms of sleep breathing-related disorders in the multi-ethnic population of Singapore (3 million people, comprising $75 \%$ Chinese, $15 \%$ Malay and $7 \%$ Indian).

A multistaged, area cluster, disproportionate stratified, random sampling of adults aged 20-74 yrs was used to obtain a sample of 2,298 subjects $(65 \%$ response), with approximately equal numbers of Chinese, Malay and Indian and in each $10 \mathrm{yr}$ age group. An interviewer-administered field questionnaire was used to record symptoms of snoring and breathing disturbances during sleep witnessed by a room-mate and other personal and health-related data.

The weighted point estimate (and 95\% confidence interval) of the whole population prevalence of snoring was $6.8 \%(5.3-8.3)$. There were pronounced ethnic differences among Chinese, 6.2\% (4.4-8.1); Malay, 8.1\% (6.1-10.2) and Indian, 10.9\% (8.5-13.4). The minimum whole population prevalence by the most restricted symptom criteria for defining sleep breathing-related disorder was $0.43 \%(0.05-0.8 \%)$. Similar marked ethnic differences in rates were observed using various symptom criteria. The ethnic differences in sleep breathing symptoms paralleled the differences in body mass index, neck circumference and hypertension, but statistically significant differences remained after adjustment for sex, age and these known associated factors.

Marked ethnic differences in snoring and sleep breathing-related disorders were observed in Chinese, Malays and Indians in Singapore, which were only partly explained by known factors of sex, age and body habitus.

Eur Respir J 1988; 12: 198-203.
Depts of *Community, Occupational and Family Medicine and **Medicine, National University of Singapore, Singapore.

Correspondence: T.P. Ng

Dept of Community

Occupational and Family Medicine

National University of Singapore

Lower Kent Ridge

Singapore 119470

Keywords: Ethnic differences

sleep apnoea syndrome

Received: August 261997

Accepted after revision March 131998

Supported by a research grant from the National Medical Research Council and the National University of Singapore.
Various studies [1-3] have reported community prevalences of habitual snoring in adults to be about 11-15\%. About $30-50 \%$ of adult habitual snorers [2] are estimated to have the sleep apnoea/hypopnoea syndrome (SAHS), which is estimated to occur in $2-4 \%$ of the general population [3-5]. Habitual snoring has been shown to be independently associated with the development of hypertension, stroke and myocardial infarction in the general population [6-8]. Habitual snorers often experience the effects of chronic sleep disruption, manifestating as excessive daytime somnolence, automatic behaviour and cognitive and affective impairment. Mild obstructive sleep apnoea has been shown to be associated with impaired quality of life characterized by greater sickness-related behavioural impairment, lower physical and emotional functioning due to poor health and poorer psychological adjustment to illness [9].

Although cases of obstructive sleep apnoea have been documented in Singapore, its prevalence and the prevalence of snoring and sleep-breathing disturbances is unknown. Hypertension, obesity, ischaemic heart disease and stroke are the most important causes of morbidity and mortality in Singapore. Among its multi-ethnic populations (75\% Chinese, 14\% Malay and 7\% Indian), Malays and Indians are well known to have higher risks of cardio- vascular diseases [10]. It is thus relevant to study the contribution of sleep breathing disorders to the observed ethnic differences in cardiovascular morbidity. Recent studies have also shown that African-Americans are more likely than Caucasians to have sleep apnoea syndrome $[11,12]$ and hypertension is also known to be more common amongst this ethnic group.

A population-based cross-sectional study of the adult population in Singapore was conducted to determine the prevalence of habitual snoring and sleep breathing disturbances associated with the sleep apnoea syndrome and to examine the ethnic differences of these disorders among Chinese, Malay and Indian adults.

\section{Methods}

\section{Subjects}

The subjects were chosen from a random sample of adults who were residents in public housing apartments in five residential estates in Singapore. Over $92 \%$ of the population live in publicly subsidized owner-occupied apartments. The sampling methodology employed an areaclustered, two-stage, stratified, disproportionate, random 
sampling strategy such that older persons and Malay and Indians were oversampled. This provided approximately equal numbers of persons in each ethnic and $10 \mathrm{yr}$ age group for the sample, so that precise sample estimates of the rates for these subgroups were obtained, based on large numbers of persons. Within each housing estate (area), a random sample of one in 10 apartment blocks was chosen and stratified random sampling of apartment units and occupants was employed to obtain one eligible adult in each household for interview. The response rate was $65 \%$, with most of the nonresponses due to occupants "not-at-home". These noncontactable households were ascertained to be largely due to nonoccupancy of the selected housing units because of the high level of residential and travel mobility of the population. Only $4 \%$ of the subjects on the sampling list refused to be interviewed.

\section{Interview questionnaire}

Subjects were interviewed in their homes by trained investigators who administered a structured questionnaire that contained questions on snoring and sleep disturbances (see Appendix). Sleep disturbances include reported breath cessations leading to partial or full arousals, manifested by kicking and moving around during sleep, choking, gasping and appearing suffocated, or abrupt awakenings in the middle of sleep. The recording of symptom res-ponses was corroborated by someone at home who shared the room or bed with the respondent. Additional questions included reported histories of hypertension and selfreported height and weight. Neck circumference was measured with a tape measure at the widest point.

The frequencies of sleep breathing disturbances were graded as never, rarely (less often than 1 night a month), sometimes (1-3 nights a month), often (1-2 nights a week), usually (3-5 nights a week) and always (every night). Habitual snoring was defined as frequent loud snoring occurring at least 3 nights per week, consistent with the definition employed in other studies, so as to facilitate comparability of results.

Recent studies [13-17] have supported the validity of sleep symptom questionnaires in population studies of sleep disordered breathing, with sleep apnoeas being well predicted by snoring and room-mate-observed symptoms of apnoea during sleep ("abnormal nocturnal respirations"). Predictive power is improved by including sex and body mass index (BMI) or wide neck circumference and hypertension. Most studies, however, have not found sleep apnoea to be significantly related to daytime symptoms of excessive somnolence, including feeling unrefreshed after sleep, morning headaches, automatic behaviour and cognitive impairment, since many persons without sleep apnoea also report these symptoms. In this study, therefore, the syndrome of "sleep breathing-related disorder" was defined by the triad of habitual snoring, sleep disturbances indicating sleep apnoea and/or hypertension or wide neck circumference. As a measure of body habitus, wide neck circumference was preferred over BMI because there is evidence to indicate that it is a more powerful predictor than BMI of sleep disordered breathing (SDB) and in one study almost entirely explained the known higher male sex risk of SDB [18].

\section{Statistical analysis}

Stratified analysis of categorical variables was employed to calculate prevalence rates of habitual snoring and other sleep breathing disturbances, specified for sex, age (in three age groups: 20-39, 40-59, and 60-74 yrs) and ethnicity (Chinese, Malay and Indian). Direct standardization procedures which applied the age-specific rates in the sample to the demographic distribution of the general population were used to obtain the weighted estimate of the whole population rates for each sex and ethnic group. The weightings used were reflected by the demographic distribution of adults in the sample $(n=2,298)$ and in the census general population $(n=1,779,750)$ shown in table 1. Comparisons of rates between ethnic groups and sex were made by calculating the adjusted (standardized) rates for each ethnic group (correcting for sex and age differences) and for each sex (correcting for ethnic and age differences). The Mantel-Haenszel procedure and its extensions for analysis of categorical variables from the Statistical Analysis Software (SAS) System were used for significance testing. Adjusted mean values of BMI and neck circumference were also calculated and significance testing was performed by analysis of covariance, using the generalized linear modelling (GLM) procedures in the SAS software package to correct for sex, ethnicity or age where appropriate.

\section{Results}

The point estimate of the prevalence of habitual snoring weighted for the demographic distribution of the whole adult population of Singapore was $6.8 \%$ (95\% confidence

Table 1. - Demographic data of study sample $(n=2,298)$ and Singapore whole population (Singapore Sleep-Breathing Disorder Study, 1995)

\begin{tabular}{|c|c|c|c|c|c|c|c|c|}
\hline & \multicolumn{4}{|c|}{ Male } & \multicolumn{4}{|c|}{ Female } \\
\hline & $20-39$ yrs & $40-59$ yrs & $60-74$ yrs & All ages & $20-39$ yrs & $40-59$ yrs & $60-74$ yrs & All ages \\
\hline \multicolumn{9}{|l|}{ Study sample: } \\
\hline Chinese & 139 & 142 & 52 & 333 & 198 & 211 & 63 & 472 \\
\hline Malay & 191 & 139 & 84 & 414 & 164 & 155 & 41 & 360 \\
\hline Indian & 163 & 133 & 61 & 357 & 165 & 163 & 34 & 362 \\
\hline All ethnicity & 493 & 414 & 197 & 1104 & 527 & 529 & 138 & 1194 \\
\hline \multicolumn{9}{|c|}{ Whole population: } \\
\hline Chinese & 418,261 & 224,212 & 64,872 & 707,345 & 404,043 & 222,113 & 80,198 & 706,354 \\
\hline Malay & 79,063 & 28,296 & 12,543 & 119,902 & 75,473 & 30,359 & 10,873 & 116,705 \\
\hline Indian & 38,357 & 20,935 & 11,962 & 71,254 & 36,675 & 17,076 & 4439 & 58,190 \\
\hline All ethnicity & 535,681 & 273,443 & 89,377 & 898,501 & 516,191 & 269,548 & 95,510 & 881,249 \\
\hline
\end{tabular}


Table 2. - Prevalence rates of frequent loud snoring by sex and ethnicity (Singapore Sleep-Breathing Disorder Study, 1995)

\begin{tabular}{llcccccc}
\hline & \multicolumn{3}{c}{ Sample estimates } & & \multicolumn{2}{c}{$\begin{array}{c}\text { Singapore population } \\
\text { weighted estimates }\end{array}$} \\
\cline { 2 - 4 } & Males & Females & $\begin{array}{c}\text { Total } \\
\text { crude }\end{array}$ & $\begin{array}{c}\text { Total } \\
\text { adjusted* }\end{array}$ & & $\begin{array}{c}\text { Weighted } \\
\text { crude }\end{array}$ & $\begin{array}{c}\text { Weighted } \\
\text { adjusted* }\end{array}$ \\
\hline Chinese & $10.8(36)$ & $3.2(15)$ & $6.3(51)$ & $6.8(4.9-8.7)$ & & $6.2(4.4-8.1)$ & $6.3(4.4-8.1)$ \\
Malay & $13.8(57)$ & $3.6(13)$ & $9.0(70)$ & $8.6(6.6-10.6)$ & & $8.1(6.1-10.2)$ & $8.4(6.3-10.5)$ \\
Indian & $16.0(57)$ & $6.3(23)$ & $11.1(80)$ & $11.0(8.6-13.4)$ & & $10.9(8.5-13.4)$ & $10.3(7.9-12.6)$ \\
Total & $13.6(150)$ & $4.3(51)$ & $8.7(201)$ & - & & $6.8(5.3-8.3)$ & - \\
\hline
\end{tabular}

The number of subjects is shown in parenthesis. *: adjusted to the age and sex distribution of the sample and the Singapore population, respectively. The weighted crude Singapore population rates are not adjusted to the standard Singapore age and sex distribution.

interval (CI): 5.3-8.3) (table 2). Males were three times more likely than females to be habitual snorers (table 2), with the odds ratio of association with snoring, adjusted for age and ethnicity, for males relative to females: 3.37 (95\% CI: $2.41-4.70)$. Within the age range from 20-74 yrs, there was an age-related increase in snoring (fig. 1; Mantel-Haenszel Q-statistic for linear association with 1 $\mathrm{df}=20.2, \mathrm{p}=0.0001$, correcting for sex and ethnicity). Ethnic differences were also observed, with Malays and Indians having higher rates of habitual snoring than Chinese, after adjusting for sex and age (Mantel-Haenszel Q-statistic for general association with $2 \mathrm{df}=9.12, \mathrm{p}=0.01$ ).

The prevalence levels and demographic differences were also analysed by combining snoring with reported symptoms of sleep disturbance indicating apnoea and hypertension or wide neck circumference. As an example, the

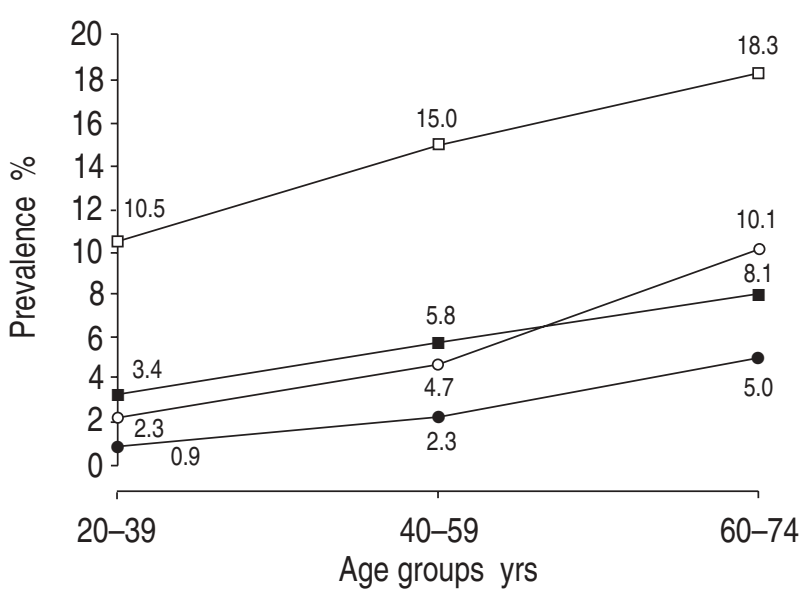

Fig. 1. - Age-specific prevalence of habitual snoring and sleep breathing-related disorder (III) by sex. $\square$ : habitual snoring male; O: habitual snoring, female; $\mathbf{\square}$ : sleep breathing-related disorder (III), male; $\bullet$ : sleep breathing-related disorder (III), female. syndrome of sleep breathing-related disorder (III: defined as habitual snoring, and symptoms of sleep disturbances or hypertension/wide neck circumference), was present in $2.1 \%$ of the whole population and showed the same pattern of specific rates for sex, age and ethnic groups as for snoring (table 3 and fig. 1). The minimum whole population prevalence based on the most restrictive criteria (frequent loud snoring, apnoeic symptoms during sleep and wide neck circumference/hypertension) was $0.43 \%$ (table 4). Similar demographic variations by sex, age, and ethnicity for these other operationally defined sleep breathing-related disorders were observed (data not shown).

The ethnic differences in prevalence of sleep breathingrelated disorders (table 5) showed that Malays and Indians had markedly greater rates of these disorders than the Chinese. It can also be seen that the mean BMI and the prevalence of obesity and hypertension were also higher in Malays and Indians. The odds ratio of association, after adjusting for these risk factors (together with age and sex), was to some extent reduced, suggesting that a small part of the greater risks in Malays and Indians was accounted for by the higher prevalence of obesity and hypertension in these ethnic groups (table 6). However, significantly higher risks in these ethnic groups remained after adjusting for these and other variables, including family history, suggesting that yet unknown factors probably play a role in these ethnic differences.

\section{Discussion}

This study showed a self-reported frequency of habitual loud snoring of $6.8 \%$ in the adult population of Singapore. There was a clear ethnic difference in the prevalence of snoring, with Chinese having the lowest prevalence $(6.3 \%)$

Table 3. - Prevalence rates of sleep-breathing related disorder (III) by sex and ethnicity (Singapore Sleep-Breathing Disorder Study, 1995)

\begin{tabular}{|c|c|c|c|c|c|c|}
\hline & \multirow[b]{2}{*}{ Males } & \multirow[b]{2}{*}{ Females } & \multicolumn{2}{|c|}{ Sample } & \multicolumn{2}{|c|}{ Singapore population } \\
\hline & & & $\begin{array}{c}\text { Total } \\
\text { unadjusted }\end{array}$ & $\begin{array}{c}\text { Total } \\
\text { adjusted } *\end{array}$ & $\begin{array}{l}\text { Weighted } \\
\text { unadjusted }\end{array}$ & $\begin{array}{l}\text { Weighted } \\
\text { adjusted* }\end{array}$ \\
\hline Chinese & $2.7(9)$ & $1.1(5)$ & $1.7(14)$ & $2.1(1.1-3.1)$ & $1.6(0.7-2.5)$ & $1.6(0.7-2.5)$ \\
\hline Malay & $5.6(23)$ & $2.2(8)$ & $4.0(31)$ & $3.9(2.5-5.3)$ & $3.5(2.2-4.8)$ & $3.7(2.4-5.1)$ \\
\hline Indian & $7.0(25)$ & $3.3(12)$ & $5.1(37)$ & $5.1(3.5-6.8)$ & $5.0(3.3-6.7)$ & $4.5(3.0-6.0)$ \\
\hline All & $5.2(57)$ & $2.1(2.5)$ & $3.6(82)$ & - & $2.1(1.4-2.8)$ & - \\
\hline
\end{tabular}

Sleep breathing-related disorder (III) $=$ snoring and apnoeic symptoms during sleep or wide neck circumference/hypertension. The number of subjects is shown in parenthesis. *: adjusted to the age and sex distribution of the sample and the Singapore population, respectively. 
Table 4. - Whole population overall and sex-specific rates of sleep-breathing related disorders

\begin{tabular}{|c|c|c|c|c|}
\hline \multirow[b]{2}{*}{ Sleep breathing-related disorders } & \multicolumn{4}{|c|}{ Percentage prevalence (95\% confidence intervals) estimates } \\
\hline & Overall & Male & Female & p-value \\
\hline Frequent loud snoring & $6.8(5.3-8.3)$ & $10.5(7.8-13.2)$ & $3.05(1.84-4.25)$ & 0.000 \\
\hline $\begin{array}{l}\text { (II) Frequent loud snoring and apnoeic symptoms } \\
\text { during sleep }\end{array}$ & $1.16(0.61-1.71)$ & $1.52(0.60-2.43)$ & $0.76(0.16-1.36)$ & 0.026 \\
\hline $\begin{array}{l}\text { (III) Frequent loud snoring and apnoeic symptoms during } \\
\text { sleep or wide neck circumference/hypertension }\end{array}$ & $2.1(1.4-2.8)$ & $2.99(1.67-4.31)$ & $1.18(0.48-1.89)$ & 0.000 \\
\hline $\begin{array}{l}\text { (IV) Frequent loud snoring, apnoeic symptoms during } \\
\text { sleep and wide neck circumference/hypertension }\end{array}$ & $0.43(0.05-0.80)$ & $0.61(-0.07-0.13)$ & $0.22(-0.05-0.49)$ & 0.123 \\
\hline
\end{tabular}

Rates were adjusted to the demographic distribution of the Singapore general population. p-values of significance tests were obtained by Mantel-Haenszel and extended procedures for categorical variables.

Table 5. - Ethnic differences in adjusted rates of sleep-breathing disturbances and associated predictors of sleep apnoea syndrome

\begin{tabular}{|c|c|c|c|c|c|c|}
\hline & & \multicolumn{5}{|c|}{ Mean and percentage prevalence (95\% confidence interval $(\mathrm{CI})$ ) estimates } \\
\hline & & Overall & Chinese & Malay & Indian & p-value \\
\hline (I) & Frequent loud snoring & $6.8(5.3-8.3)$ & $6.3(4.4-8.1)$ & $8.4(6.3-10.5)$ & $10.3(7.9-12.6)$ & 0.01 \\
\hline (II) & $\begin{array}{l}\text { Frequent loud snoring and apnoeic } \\
\text { symptoms during sleep }\end{array}$ & $1.16(0.61-1.71)$ & $0.83(0.17-1.49)$ & $2.31(1.23-3.39)$ & $2.37(1.21-3.53)$ & 0.04 \\
\hline (III) & $\begin{array}{l}\text { Frequent loud snoring and apnoeic } \\
\text { symptoms during sleep or wide neck } \\
\text { circumference/hypertension }\end{array}$ & $2.1(1.4-2.8)$ & $1.6(0.7-2.5)$ & $3.7(2.4-5.1)$ & $4.5(3.0-6.0)$ & 0.002 \\
\hline (IV) & $\begin{array}{l}\text { Frequent loud snoring, apnoeic } \\
\text { symptoms during sleep and wide neck } \\
\text { circumference/hypertension }\end{array}$ & $0.43(0.05-0.80)$ & $0.29(0.15-0.73)$ & $0.99(0.32-1.67)$ & $0.84(0.13-1.54)$ & 0.34 \\
\hline \multicolumn{7}{|c|}{ Body mass index $\mathrm{kg} \cdot \mathrm{m}^{-2}$} \\
\hline & Adjusted mean $(95 \% \mathrm{CI})$ & $24.0(23.6-24.4)$ & $22.9(22.2-23.6)$ & $24.8(24.1-25.5)$ & $24.2(23.5-24.9)$ & 0.001 \\
\hline & $\%$ Š $2.5 \mathrm{~kg} \cdot \mathrm{m}^{-2}$ & $26.6(24.4-28.7)$ & $18.8(15.6-22.0)$ & $30.6(26.6-34.6)$ & $31.1(27.0-35.2)$ & 0.000 \\
\hline \multicolumn{7}{|c|}{ Neck circumference $\mathrm{cm}$} \\
\hline & Adjusted mean $(95 \% \mathrm{CI})$ & $35.9(35.7-36.0)$ & $35.5(35.3-35.7)$ & $36.0(35.8-36.2)$ & $36.6(36.3-36.8)$ & 0.001 \\
\hline & $\%>95$ th percentile value & $6.2(5.2-7.3)$ & $4.7(3.0-6.4)$ & $8.0(6.0-10.0)$ & $6.5(4.6-8.4)$ & 0.003 \\
\hline Histo & ory of hypertension & $8.6(7.5-9.8)$ & $7.8(5.8-9.6)$ & $8.8(6.9-10.8)$ & $8.0(7.8-12.1)$ & 0.04 \\
\hline
\end{tabular}

Rates were adjusted to the demographic distribution of the Singapore general population. p-values of significance tests were obtained by analysis of covariance for continuous variables and Mantel-Haenszel and extended procedures for categorical variables.

Table 6. - Odds ratio of association of sleep breathing-related disorders in Malays and Indians relative to Chinese, adjusted for cardiovascular risk factors

\begin{tabular}{|c|c|c|c|c|c|c|}
\hline \multirow[b]{2}{*}{ Covariate adjustment } & \multicolumn{3}{|c|}{ Snoring } & \multicolumn{3}{|c|}{ Sleep breathing-related disorder (III) } \\
\hline & Chinese & Malay & Indian & Chinese & Malay & Indian \\
\hline Age, sex & 1.00 & $1.29(0.88-1.90)$ & $1.74(1.20-2.54)$ & 1.00 & $2.34(1.21-4.54)$ & $3.12(1.63-5.96)$ \\
\hline Age, sex, family history & 1.00 & $1.26(0.86-1.85)$ & $1.70(1.17-2.48)$ & 1.00 & $2.28(1.19-4.35)$ & $3.02(1.57-5.78)$ \\
\hline Age, sex, obesity & 1.00 & $1.21(0.82-1.77)$ & $1.66(1.14-2.42)$ & 1.00 & $2.11(1.08-4.12)$ & $2.90(1.51-5.55)$ \\
\hline Age, sex, hypertension & 1.00 & $1.29(0.88-1.87)$ & $1.71(1.17-2.48)$ & 1.00 & $2.29(1.17-4.48)$ & $2.86(1.48-5.52)$ \\
\hline $\begin{array}{l}\text { Age, sex, family history, } \\
\text { obesity and hypertension }\end{array}$ & 1.00 & $1.17(0.79-1.72)$ & $1.60(1.10-2.34)$ & 1.00 & $2.01(1.02-3.98)$ & $2.65(1.37-5.15)$ \\
\hline
\end{tabular}

III: frequent loud snoring and apnoeic symptoms during sleep or wide neck circumference/hypertension.

and Indians having the highest (11\%). The prevalence in Indians was similar to that shown in other studies of Caucasian populations, which is about $11-15 \%$, using similar defining criteria. It is unlikely that the prevalence estimates in this sample survey were seriously biased by the level of response rate $(65 \%)$, as most of the subjects were not available for study because of social reasons which were unrelated to the snoring or sleep apnoea syndrome. Only $3-5 \%$ of eligible subjects in each housing estate refused to be interviewed and this is not likely to bias the results very much. Nonrespondents are probably likely to include more snorers since these people may perceive the condition as personally embarrassing. Hence, the present results are likely to underestimate the true prevalence of snoring in the population. The possibility of differential nonresponse influencing the observed ethnic differences should be considered. The response rates were indeed better in Indians and Malays than in Chinese, but it is well known that the reasons are almost entirely cultural and not health related, as observed in numerous previous diverse surveys. It is also unlikely that the results were seriously biased by differences in response rates between sex and age groups, although there was no information to support this. Higher rates of snoring in males (which is very marked indeed) and in older people have been consisten-tly observed in many previous studies $[1,5,12]$, so the present results are a likely reflection of the true situation. The results for BMI, obesity and hypertension in this study are also very 
similar to those obtained from previous repeat surveys of cardiovascular risk factors in the population.

The validity of the responses from a questionnaire interview is an important consideration in evaluating the prevalence estimates of sleep breathing-related disorders in the population. All-night polysomnographic data are generally adopted as the gold standard of defining sleep apnoea/hypopnoea syndrome and portable recording devices have been used in community studies of sleep apnoea disorders. However, different cut-off levels in the apnoeahypopnoea score $\left(5,10\right.$ or 15 episodes $\cdot h^{-1}$ of sleep), reflecting the varying severity of the condition, have been employed to define the syndrome, with varying false-positive and negative rates, suggesting that there is no clear clinical demarcation of the clinical condition from normality, with nonapnoeic snoring representing the other end of the continuum of sleep breathing-related disorders. Validation studies have demonstrated higher rates of falsepositive results in elderly persons and low night-to-night reproducibility has been reported in validation studies [19-21]. Scientific information on the validity of portable recording devices is even more limited [22] and different instruments show varying results in terms of their sensitivity and specificity. Sleep symptom questionnaire data have been shown to provide a valid means of characterizing symptom distributions in population surveys of obstructive sleep apnoea [13-17] and have been usefully employed in many community studies.

The operational criteria for defining sleep breathing disorders from a symptom questionnaire are necessarily difficult and arbitrary. Several combinations of symptom and self-reported variables are possible to define "sleep brea-thing-related disorder". While some evidence from previous studies supports these entities as encompassing actual sleep apnoea syndrome, direct comparison of prevalence rates with other studies, except for snoring frequency, are not strictly valid and at best only indicative. Nevertheless, the authors are confident that the comparison of ethnic differences using these surrogate variables of true sleep apnoea syndrome is a valid reflection of the relative frequ-encies of the disorder in Chinese, Malays and Indians.

Given the limitations of this study, it is remarkable how well known relationships of sleep apnoea/hypopnoea syndrome with demographic variables such as sex and age, as well as other risk factors, such as obesity and hypertension, which are consistently reported in the literature, were demonstrated. The greatest interest in the present report concerns the ethnic differences in the prevalence of sleep breathing-related disorders, of which there are few reports in the literature. The greater risks of sleep breathing-related disorders in Malays and Indians are indeed remarkable. Given that these groups are known to have higher frequencies of cardiovascular risk factors and disease, the consistent impression that emerges from this study is that sleep breathing-related disorders are an important contributory factor in cardiovascular morbidity in these ethnic groups. Genetic factors, indicated by the influence of family history, may play a part but, nevertheless, the results also indicate that other, yet unknown, factors remain to be accounted for. This issue needs to be studied further in future investigations.

In conclusion, this study reported on community prevalences of snoring and symptoms of sleep breathing-rela- ted disorders in Singapore, which were consistent with those reported elsewhere. Markedly higher risks of these disorders were noted in Malays and Indians, consistent with the higher risk of cardiovascular morbidity from obesity and hypertension in these ethnic groups. These risk factors contribute to a small extent to the ethnic differences, but a great deal of the ethnic variations in sleep breathing disorders remains to be elucidated.

\section{Appendix: Questionnaire on snoring and sleep disturbances}

As far as anyone in your family (including yourself) can tell:

How often do you snore loudly in your sleep?

How often do you kick around and move around a lot during sleep?

How often do you wake up at night appearing suffocated or choking?

How often do you gasp or choke while sleeping?

How often do you stop breathing, or hold your breath while sleeping?

How often do you feel a strong urge to sleep during the day?

How often do you intentionally take a nap during the day?

How often do you fall asleep when you relax immediately before or after dinner?

How often do you fall asleep in social occasions when you shouldn't?

How often do you fall asleep while driving?

\section{References}

1. Fitzpatrick MF, Martin K, Fossey E, Shapiro CM, Elton RA, Douglas NJ. Snoring, asthma, and sleep disturbance in Britain: a community-based survey. Eur Respir J 1993; 6: $531-535$

2. Cirignotta F, D'Allesandro R, Partinen M, et al. Prevalence of every night snoring and obstructive sleep apnoeas among 30-69 year old men in Bologna, Italy. Acta Neurol Scand 1989; 79: 366-372.

3. Lavie P. Incidence of sleep apnea in a presumably healthy working population: a significant relationship with excessive daytime sleepiness. Sleep 1983; 6: 312-318.

4. Gislason T, Almqvist M, Ericksson G, Taube A, Boman G. Prevalence of sleep apnea syndrome in Swedish men: an epidemiological study. J Clin Epidemiol 1988; 1: 571-576.

5. Olson LG, King MT, Hensley MJ, Saunders NA. A community study of snoring and sleep-disordered breathing. Prevalence. Am J Respir Crit Care Med 1995; 152: 711-716.

6. Koskenvou M, Kaprio J, Partinen M, Langivaino H, Sarna S, Heikkila K. Snoring as a risk factor for hypertension and angina pectoris. Lancet 1985; 1: 893-896.

7. Partinen M, Palomak H. Snoring and cerebral infarction. Lancet 1985; 2: 125-126.

8. Koskenvou M, Kaprio J, Telakivi T, Partinen M, Heikkila $\mathrm{K}$, Sarna S. Snoring as a risk factor for ischaemic heart disease and stroke. BMJ 1987; 294: 16-19.

9. Gall R, Isaac L, Kryger M. Quality of life in mild obstructive sleep apnea. Sleep 1993; 16: S59-S61.

10. Research and Evaluation Department, Ministry of Health, Singapore. The Health of Singaporeans, 1993. Ministry of Health, Singapore. 
11. Ancoli Israel S, Klauber MR, Stepnowsky C, Estline E, Chinn A, Fell R. Sleep-disordered breathing in AfricanAmerican elderly. Am J Respir Crit Care Med 1995; 152: 1946-1949.

12. Redline S, Tishler PV, Han MG, Tosteson TD, Strohl KP, Spry K. Racial differences in sleep-disordered breathing in African-Americans and caucasians. Am J Respir Crit Care Med 1997; 155: 186-192.

13. Haraldsson PO, Carenfelt C, Tingvall C. Sleep apnea syndrome symptoms and automobile driving in a general population. J Clin Epidemiol 1992; 45: 821-825.

14. Flemons WW, Whitelaw WA, Brant R, Remmers JE. Likelihood ratios for a sleep apnea clinical prediction rule. Am J Respir Care Med 1994; 150: 1279-1285.

15. Olson LG, King MT, Hensley MJ, Saunders NA. A community study of snoring and sleep-disordered breathing. Symptoms. Am J Respir Crit Care Med 1995; 152: 707710.

16. Hoffstein V, Szalai JP. Predictive value of clinical features in diagnosing obstructive sleep apnea. Sleep 1993; 16: 118-122.

17. Kump K, Whalen C, Tishler PV, et al. Assessment of the validity and utility of a sleep-symptom questionnaire. $\mathrm{Am}$ J Respir Crit Care Med 1994; 150: 735-741.

18. Young T. Analytic epidemiology studies of sleep disordered breathing - what explains the gender difference in sleep disordered breathing? Sleep 1993; 16: S1-S2.

19. Berry D, Webb W, Block J. Sleep apnea syndrome - a critical review of the apneic I index as a diagnostic criterion. Chest 1984; 86: 529-531.

20. Wittig R, Romaker A, Zorick F, Roehrs T, Conway W, Roth T. Night-to-night consistency of apneas during sleep. Rev Respir Dis 1984; 129: 244-246.

21. Kramer M, Silva C. Night to night variability of apnea. Sleep Res 1986; 15: 138-139.

22. Ferber R, Millman R, Coppola J, et al. ASDA standards of practice. Portable recording in the assessment of obstructive sleep apnea. Sleep 1994; 17: 378-392. 